\title{
Use of CAM Strategies for Tool Movement in Machining Surfaces of Various Shapes
}

\author{
FABIAN Michal ${ }^{1}$, IŽOL Peter ${ }^{2}$, TOMÁŠ Miroslav ${ }^{1}$, KUPEC František ${ }^{1}$, KOPAS Melichar ${ }^{3}$ \\ 1 Technical University of Košice, Faculty of Mechanical Engineering, Department of Automobile Production \\ 2 Technical University of Košice, Faculty of Mechanical Engineering, Department of Technology, Materials and Computer Aided Production \\ 3 Technical University of Košice, Faculty of Mechanical Engineering, Department of Machine Design and Transport Engineering
}

Abstract: Implementation of the CAD systems in the field of machine design allowed more possibilities for the design of free-form surfaces, which are especially used in the field of shape design within the automotive and consumer industries. The connection of the CAD systems with the CAM machining technologies has brought a revolution in the field of machining these surfaces. What until recently could be machined with a great effort on copy milling machines, where the clay or laminate model was an original, can now be produced using a virtual model, whereby the tool copies the shape of this model. The CAD/CAM systems already offer analyses during design, which can verify the manufacturability of the modelled surface. The CAM systems offer a number of tool movement strategies for machining a given surface. This paper is focused on the selection of the most suitable strategy for machining the shaped surfaces of the active parts of press tools for the production of automotive parts. It points out the importance of the CAD/CAM data needed in the stage of technological preparation of production, because they have a significant impact on the achieved surface quality. This paper deals with strategies of machining a planar inclined surface using horizontal and vertical machining strategies. The next part of the paper deals with machining of the Free Form Surface and the final part of the paper uses the described strategies for machining the shapes of the die cavity for connecting rod fittings. The experimental part is concentrating on the selection of the most suitable strategy of die milling for the production of the connecting rod (car internal combustion engine part). Simulations of production and the production of details from two different materials are realized on individual details of the mould. The resulting quality of the treated surface was evaluated based on the evaluation of surface roughness.

Keywords: CAM manufacturing, suitable machining strategy, surface roughness evaluation, machining quality and speed, engine parts CAM manufacturing, effective tool movement.

\section{Introduction}

Origins of the NC technology implementation describe Groover, M. in [1] and Chang, C.H. with Melkanoff in [2]. Origins of NC programming were characterized by tool movement programming using APT language that has been developed to control NC machines in 1958. The next intense development of NC machinery control starts with beginning of 3D modeling using CAD systems. These systems allow CNC code generation by CAM modules since 70-ies last century as well. The surface modeling allows free form surfaces creation and 5-axis CNC machines make possible any surfaces designing and machining. Mentioned in combination with injection moulding of plastics as well as metal sheets forming have strong influence to design of consumer and automotive industry products [3], [4], [5].

The main objective in beginnings of NC machines was to make the required shape. 
Nowadays, the main objective turns to make the required shape fastest and cheapest, that means most effective. The influence of CAM parameters set up to the quality of free form surfaces is researched by Fabian et al. in [6] and lžol et al. in [7], [12], [13]. The problem is researched in the research centres collaborating with consumer and automotive industry and using the CNC technology to machine tools and forming dies surfaces as well [8], [9], [10], [11], [14].

The production of forming tools or molds is related to forging, pressing, casting or injection molding technologies. These technologies are described by Kalpakjian in his work [15], but also by other professional works such as [16], [17] and [18]. The resulting quality of manufactured tools significantly affects the quality of manufactured components. For this reason, the influence of tool choice and machining strategy on the production of molds or forming tools needs to be carefully considered. The term "machining strategy" is a predefined toolpath in a CAM system that is optimized to machine various shaped surfaces to produce the final product with the highest possible efficiency [18].

\section{Tool movement}

The tool movement during milling consists of three types of movements. The first is the movement of the tool during machining, also called the working movement. During this type of movement, the material is removed. Three-axis milling also involves moving the work table. The second is the movement of the tool into and out of the frame. The third is the movement of the stroke and the movement out of the working plane in order to quickly move the tool to the next working movement of the tool. By various combinations of these movements, it is possible to optimize working time, which significantly affects production costs. Especially in the production of shaped surfaces, there is the potential for a combination of movements in order to speed up production while maintaining the achieved product quality. As stated by the authors in Yao and Gupta in [19], the exclusion of nonworking movements, i.e. the complete elimination of movements without machining, is not possible.

Hybrid NC systems currently allow different combinations of machining strategies to be selected in one operation. According to the shape of the required workpiece area, a suitable cutting path pattern is assigned. The combination is selected from several alternatives. Especially with shaped surfaces, there is a possibility of savings - for example in the form of a shortening of the milling tool path by 10 to $40 \%$. Current methods of selecting the appropriate strategy in CAM systems still require the experience of a technologist and NC programmer to determine the dimensions of the tool and the distances of adjacent toolpaths, which also affect the resulting product quality.

One of the analytical methods for CNC machining of shaped surfaces is based on five steps:

\section{Finding the surface equation}

\section{Analysis of its curvature}

\section{Choice of tools}

4. Calculation of the deviation between the required and the obtained surface

\section{Calculation of MSH, i.e. the distance of adjacent toolpaths}

The distance between the toolpaths $a_{e}$ is determined by the equation:

$$
\frac{a_{e}}{2 r}=\sqrt{1-\left(\frac{r-S H}{r}\right)^{2}}
$$

where: SH (Scallop Height) - height of inequality (Fig. 1), $r$-tool radius

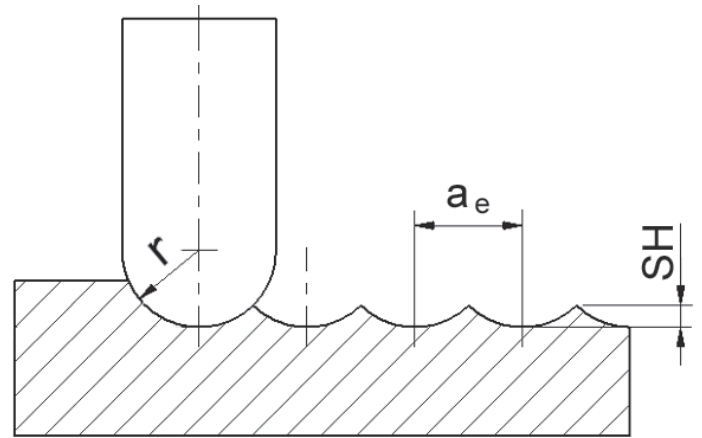

Figure 1: Graphical representation of parameters from equation 1.

In practice, when creating an NC program, the feed rate value is often entered with regard to the most unfavourable conditions that can occur during the machining path. The adapted low speed thus increases the machining time. The elimination of this shortcoming is a smooth change in the feed rate during machining. Several principles are also used:

- Principle of maintaining a constant cutting force - the value of the cutting force is calculated from the parameters of the cutting process 
- The principle of maintaining a constant removal of material

- Principle of keeping the chip thickness constant

\section{Machining the sloping surface}

The principle of inclined surface machining can be described in the following example. Semifinished aluminium bar blanks were used as samples. The block size was chosen 25×25×30 mm. Fig. 2 shows the modeled samples for the creation of the NC milling program in the CAM module of the Catia V5 design CAD system. The isoparametric machining strategy was used. The EMCO Concept MILL 155 three-axis milling machine was used to machine the inclined surface.
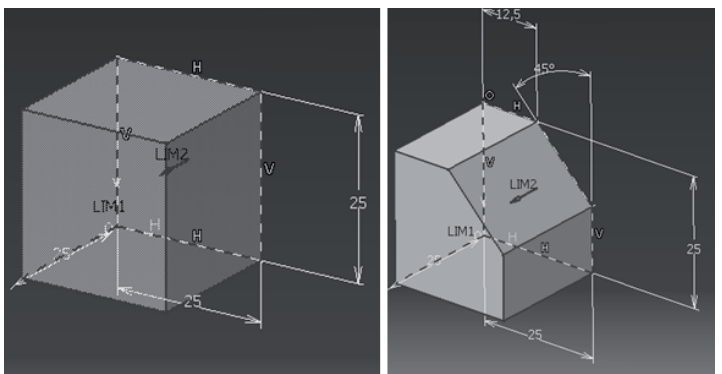

Figure 2: Samples modeled in the Catia V5 CAD system.

\section{The principle of machining a sloping surface - vertically}

The term vertical machining characterizes the movement of the tool in the $Z$ axis and the machine table in the direction of the $Y$ axis. The tool performs a small working movement. Four one-way strategies of oblique machining of the shaped surface are investigated on the sample.

- Ascending down milling

- Ascending up milling

- Descending down milling

- Descending up milling

These strategies are shown in Figure 3. The movement of the copying knife is schematically shown in Figure 4, where the imprint of the cutting tool can be seen on the left during downward milling, on the right the imprint of the cutting tool during upward milling.

\section{The principle of sloping surface machining - horizontally}

The term horizontal machining characterizes the movement of the machine table in the working axis $X$ by a smaller working movement. Figure 5 schematically shows four horizontal types of oneway sloping strategies.

- Ascending down milling

- Ascending up milling
- Descending down milling

- Descending up milling
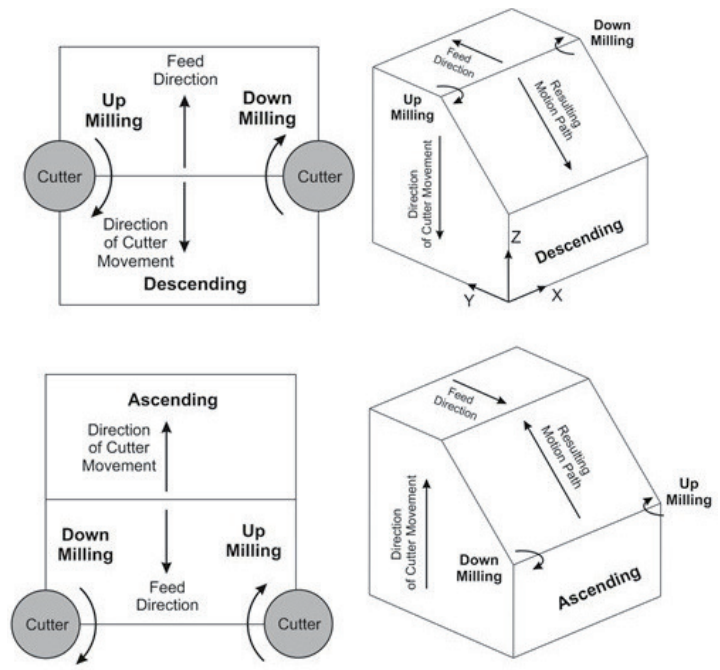

Figure 3: Schematic representation of the movement of the cutting tool during vertical milling.

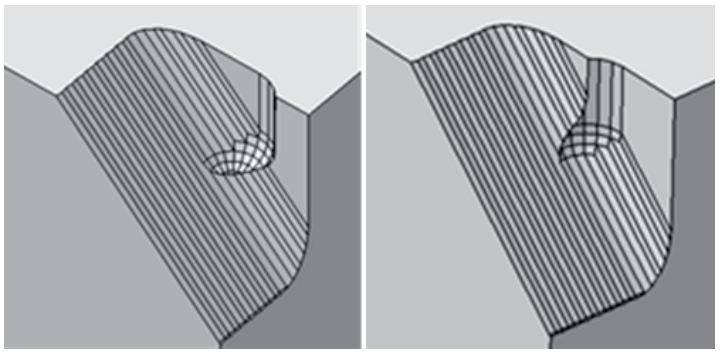

Figure 4: Copying cutter imprint - vertical milling: descending - up (left), ascending - down (right).
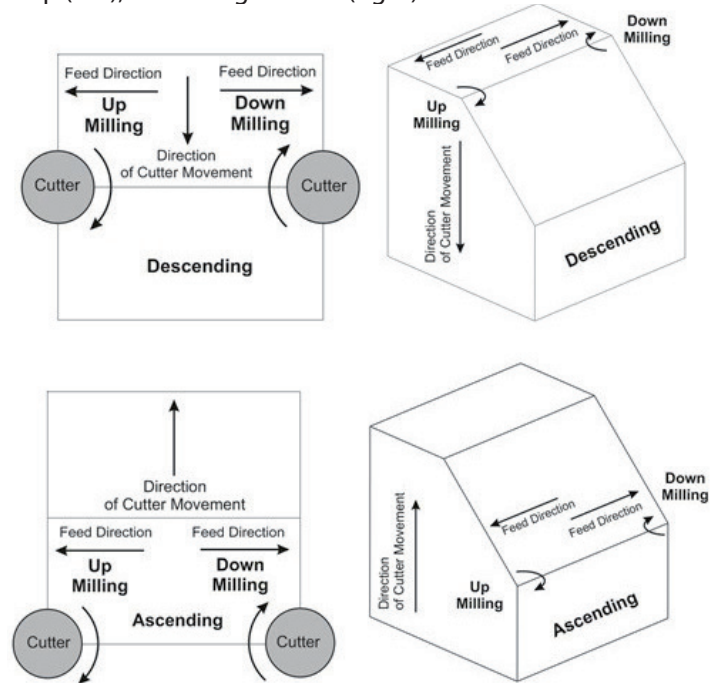

Figure 5: Schematic representation of the movement of the cutting tool during horizontal milling. 
As in the case of vertical machining, the movement of the copying knife in horizontal milling is shown in Figure 6. On the left in this figure, the imprint of the cutting tool is up and down on the left and down on the left during upward milling.

The horizontal milling of the inclined surface was set to two different maximum pitch heights for illustration. The first was $\mathrm{MSH}=0.01 \mathrm{~mm}$ and the second $\mathrm{MSH}=0.05 \mathrm{~mm}$. The selected machining strategy for horizontal milling has a minimal effect on the quality of the finished surface at both maximum pitch heights MSH when machining with a copying tool.

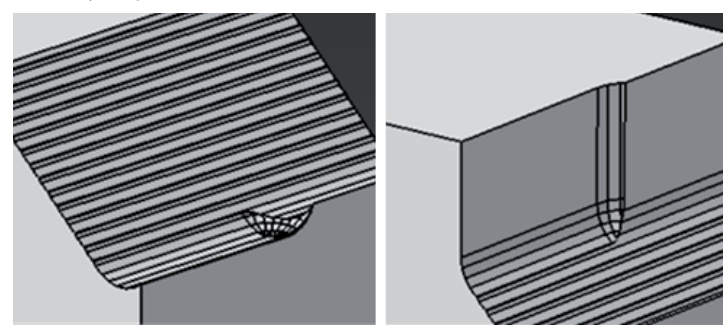

Figure 6: Copying cutter imprint - horizontal milling: descending upward (left) and ascending downward (right).

In the case of vertical inclined milling, machining was also performed in two different settings. Maximum pitch height $\mathrm{MSH}=0.01$ and $\mathrm{MSH}=$ $0.05 \mathrm{~mm}$. The effect on the quality of the machined surface machined with the copying knife was minimal for both settings.

\section{Machining the shaped surface}

Data from geometric and volume analysis of the shape are used for automatic creation of the NC program. However, the physical analysis of the process of machining the shaped surface is not taken into account. To eliminate this shortcoming and optimize the machining process, an approach based on the evaluation of material removal MRR (Material Removal Rate) is used. Based on this approach, the feed rate is inversely proportional to the average or instantaneous volume reduction. According to Erdim (143921-18), however, the MRR approach increases the feed values and at the same time the cutting force values up to the desired values. It therefore recommends combining this approach with an approach to evaluating the value of the cutting force. Machine times are thus reduced by $45 \div 65 \%$.

\section{NURBS curves and surfaces}

Current CAD systems, in which components are designed for NC machining, use a mathematical description and a way of representing geometric bodies in the form of NURBS curves and surfaces. The basis for these areas are control points. Changing their shape is possible by changing the position of the control points but also by rationality, i.e. weight and node vector. The NURBS curve is defined by the Selimovic's relation [21]:

$$
C(t)=\frac{\sum_{i=0}^{m} w_{i} P_{i} N_{i}^{n}(t)}{\sum_{i=0}^{m} w_{i} N_{i}^{n}(t)}
$$

where: $m$ - number of control points, $n$ - number of points affecting the local area, $w_{i}$ - weights of individual control points $P_{i^{\prime}} N_{i}^{n}(t)$ - normalized basis functions of the degree, $t \in\left\langle t_{n}, t_{m+1}\right\rangle$ - node vector, specifying where and how a given control point affects the curve.

The NURBS surface is then formed as a tensor product of two NURBS curves. The general notation for a NURBS desktop is:

$$
S(u, v)=\frac{\sum_{i=0}^{q} \sum_{j=0}^{r} w_{i j} P_{i j} N_{i}^{m}(u) N_{j}^{n}(v)}{\sum_{i=0}^{q} \sum_{j=0}^{r} N_{i}^{m}(u) N_{j}^{n}(v)}
$$

In [22], samples were proposed for the purpose of comparing the four most used strategies for machining shaped surfaces designed using NURBS curves. The creation of NC programs was realized in one of the available CAM systems. The comparisons were performed on a sample with a freely modeled shaped surface with a planar part in one of the corners. The material to be machined was dural 424201 (AlCu4Mg). The dimensions of the blank were $47 \times 47 \times 20 \mathrm{~mm}$. The milling strategies available in SolidCAM, which was integrated into the SolidWorks CAD environment, were used. Samples were made in one roughing and one finishing operation. The roughing method was common to all samples produced to ensure a level playing field for the finishing strategies being compared. The $\varnothing 18$ mm Korloy AMS $2018 S$ face milling cutter with the APXT 11T3PDR-MA insert was intended for roughing, and the $\varnothing 10 \mathrm{~mm}$ ZPS HSS Co8 copy milling cutter was used for finishing. The cutting conditions were chosen to take into account the type of material being machined and the technical 
parameters of the EMCO Concept Mill 155 3-axis CNC milling machine with the Heidenhain TNC 426 control system.

The ZIG-ZAG strategy was used as a roughing, using a set of horizontally arranged layers, the height of which is defined by the specified depth of cut. In each layer, the tool moves in linear paths up to the contour of the shape in the given layer, which bypasses the defined allowance value. This method is suitable for the production of basic shapes of shaped surfaces by face milling. The allowance value for the next completion was set at $0.5 \mathrm{~mm}$. The state of the samples after simulation and the actual state of the samples after roughing is shown in Figure 7.

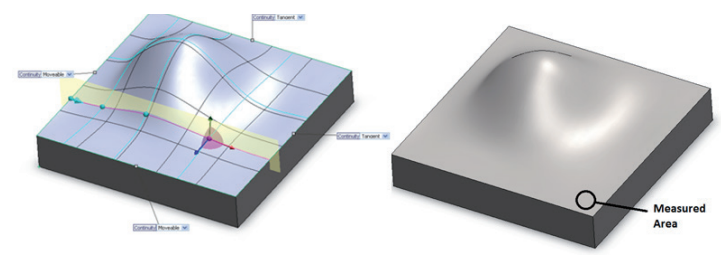

Figure 7: Proposed samples.

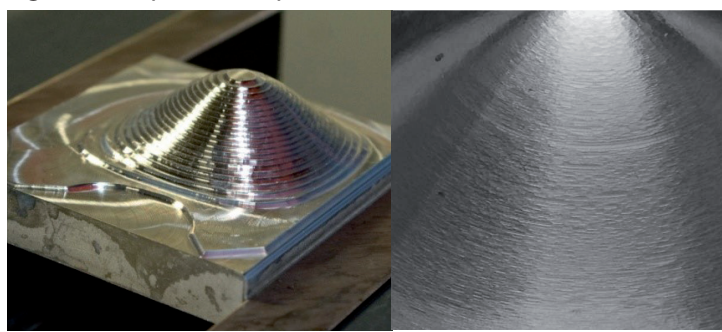

Figure 8 Status of a surface after roughing operation and detail of the final real surface.

Visually, the appearance of the fabricated surface of each sample was compared with the surface presented by the simulation (Fig. 8). From the comparison of the simulated and the actually made surface, the best agreement was achieved in the spacing strategy. The biggest differences were shown in the strategy of constant Z. The sample showed significant irregularities in the corner parts, which was not shown by the simulation. However, this strategy is preferably intended for steep surfaces and is therefore not suitable for planar parts of workpieces.

The final roughness of the product was taken into account when evaluating the surface quality. The construction of a flat surface proved to be the most problematic here. The values of roughness Rz measured here ranged from 3.51 to $11.27 \mu \mathrm{m}$ (Fig. 9). This represents 0.44 to 1.41 times the defined value of the height of the inequalities, with the best approximation being achieved with the spiral strategy. For the surface obtained by the spacing strategy, the value of Rz was larger than the set value of the height of the irregularities. The graph also shows the constantly set Scallop Height value for all assessed strategies equal to $0.008 \mathrm{~mm}$.

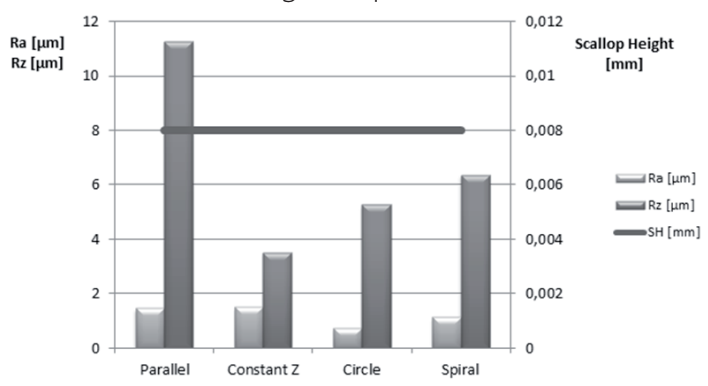

Figure 9: Comparison of surface roughness obtained by different machining strategies.

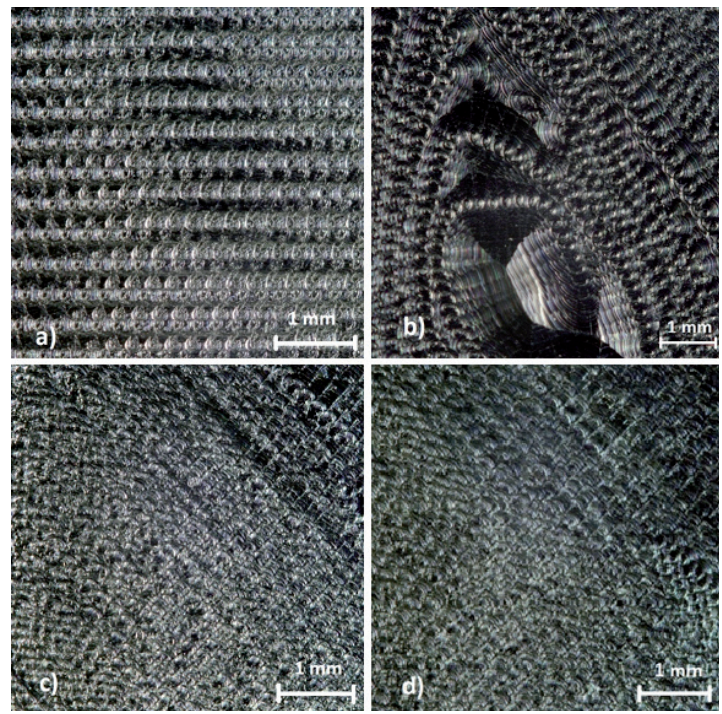

Figure 10: Machined surface textures for strategy a) Parallel, b) Constant Z, c) Circle and d) Spiral Milling.

For the selected sample shape, the strategy with a helical tool path proved to be the most advantageous, because it obtained a surface roughness, closest to the specified value of the height of the unevenness, even in critical places of the sample shape. A similar result was achieved with the strategy of creating circular toolpaths. On the contrary, the blending strategy proved to be unsatisfactory for the given shape due to the highest achieved surface roughness $R z$, exceeding the value of the specified height of unevenness. In another strategy, constant $Z$, the lowest surface roughness 
value Rz was achieved, but also the uneven surface texture in the planar part of the sample.

In the shaped parts of the samples, the compared strategies are equivalent on the basis of visual comparison, according to the performed analyses from the simulations, the largest deviations from the desired shape were constant $Z$ in the strategies.

\section{Experimental part}

For the experimental part - a demonstration of the choice of strategy for the production of the tool, the connecting rod (part of the internal combustion engine) was selected. The part model was created in the SolidWorks CAD system. The connecting rod is a common part of the automotive industry made by die forging. The metal die was developed using a CAD system according to Tomáš et al. v [20]. The

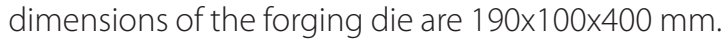
Figure 11 illustrates a connecting rod model. The forging die is shown in Figure 12.

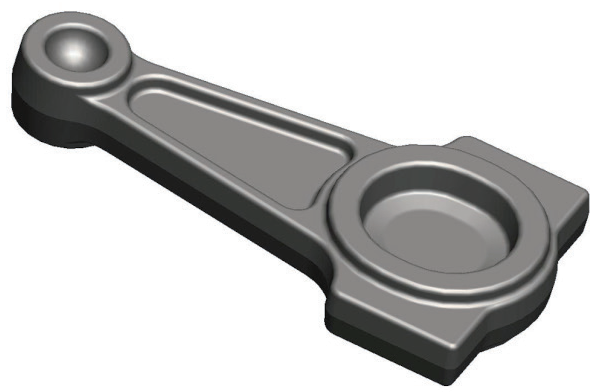

Figure 11: Model of the forget piece.

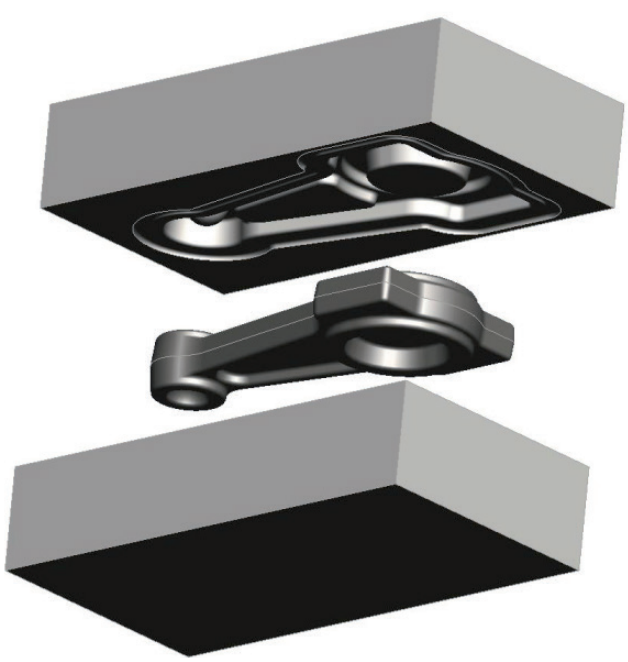

Figure 12: Model of the upper and lower part of the forging die together with the forget piece.
As can be seen in Figure 13, the forging die consists mainly of shaped surfaces combined with planes. For a more illustrative experimental part, the individual parts of the forging die were selected to create NC programs. Generating toolpaths requires first selecting tools:

- Roughing milling machine $r=18$ mm, type Korloy AMS 20185 cutting tip made of carbide

- Pre-treatment milling machine - face milling machine $r=10 \mathrm{~mm}$, type ZPS-FN with four teeth made of HSS Co8 material

- Finishing copying machine $r=8 \mathrm{~mm}$, type ZPS-FN with four teeth made of HSS Co8 material

The setting of cutting parameters was adapted to the type of material - aluminium alloy.

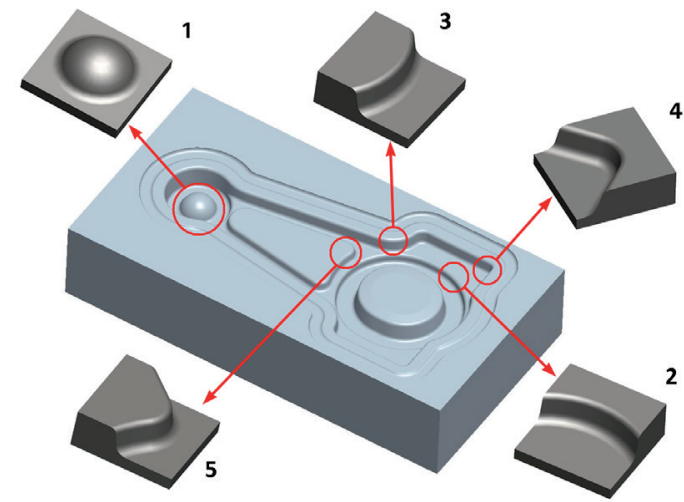

Figure 13: Elements extracted from the forging die cavity.

\section{Choice of machining strategies}

A contour strategy was selected for the roughing operation. The tool path overlap value was selected as 0.65 and the cut depth $1 \mathrm{~mm}$. The uniform contribution to the material after roughing remained $1 \mathrm{~mm}$ evenly over the entire surface of the part.

As a pre-finishing strategy, a constant height strategy in the Z-axis direction was chosen for all samples with a defined variable depth of cut in the range of 0.2 to $0.5 \mathrm{~mm}$. The $\mathrm{SH}$ value was set to 0.5 $\mathrm{mm}$ using the CAM system. The maximum defined lateral step was $3 \mathrm{~mm}$. The contribution to the material after completion remained $0.1 \mathrm{~mm}$ evenly over the entire surface of the part.

Combinations of several types of strategies were chosen for the finishing operations. Specifically, the combination of HSM strategy with constant height Z, HSM and spiral strategy, HSM and parallel lining strategy. In order to choose the most suitable strategy, they were compared in the CAM system 
with classical strategies - constant height $Z$, spiral strategy and line spacing strategy. Figure 14 shows a comparison of HSM strategy combined with constant $Z$ height compared to HSM and line spacing. The machining time in the first case was 38 minutes, in the second case it was reduced to 33 minutes due to simpler and more regular toolpaths.

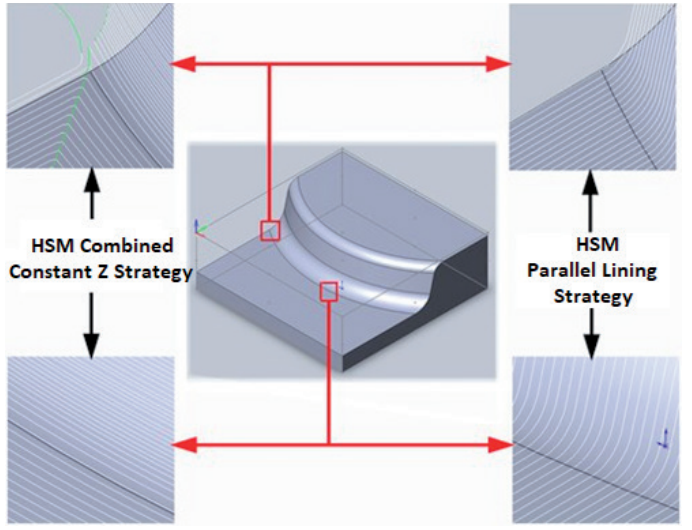

Figure 14: Tool paths of the compared strategies in two places of the sample No.3.

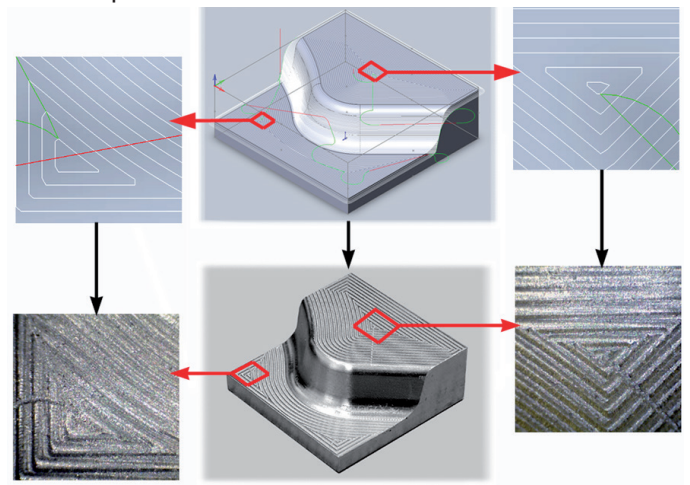

Figue 15: Comparison between the generated tool paths and tool trails on the surface of the sample No.5.

Figure 15 shows a comparison of the tool paths generated and the tool tracks after machining the surface of sample No.5.

On sample No. 4, production was carried out using the HSM strategy. In the case of experimental production on the aluminium alloy sample, the tool pathways were visible. In the case of an application for machining a sample of synthetic wood, the tool pathway was not visible. The MSH distance has been set to $0.35 \mathrm{~mm}$.

The following images show the impact of choosing an appropriate machining strategy based on a comparison of the resulting surface roughness
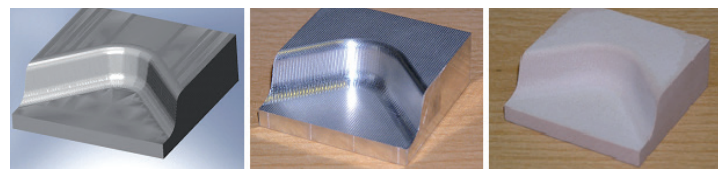

Figure 16: Sample No. 4 after CAM system simulation (left) and sample made of aluminium alloy or "artificial wood" (right).

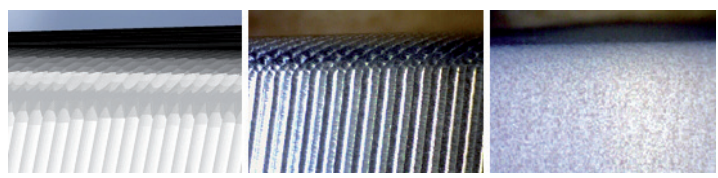

Figure 17: Comparison of tool tracks for sample no. 4 in the rounded transition area, on the left is the surface after the simulation using the CAM system, in the middle is a sample of aluminium alloy and on the right is a sample of artificial material - synthetic wood; value of ae is $0.35 \mathrm{~mm}$.

value. The MSH value was set to $0.35 \mathrm{~mm}$. For synthetic wood samples, Ra values ranged from 3.59 to 4.19 micrometres. The height of the Rz tooth profile for aluminium alloy samples ranged from 9.68 to 11.37 micrometres and, in the latter case, 22 to 22,87 micrometres.

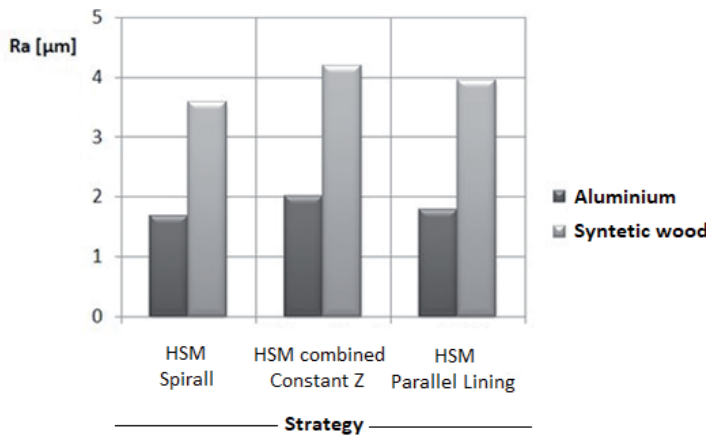

Figure 18: Comparison of surface roughness values (mean arithmetic deviation $\mathrm{Ra}$ ) obtained using different strategies.

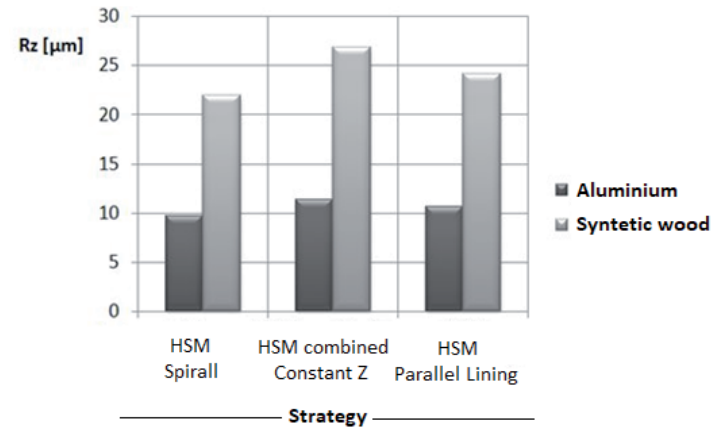

Figure 19: Comparison of surface roughness values (height of profile ridges $\mathrm{Rz}$ ) obtained using different strategies. 


\section{Evaluation}

The machining time of finishing operations was in all cases almost identical to the simulation, the highest time deviation was only 3\%. High-speed strategies have proven to be advantageous due to the continuous generation of tool trajectories so as to reduce the number of sections with repeated deceleration and repeated acceleration of the tool.

By compiling a surface roughness comparison table, it was shown that the arithmetic mean of the deviation Ra for synthetic wood was twice as high as for the aluminium alloy. In the case of the height of the tooth profile, it was 2.3 times higher. It follows that the material synthetic wood is not suitable for production of the prototypes, it is more suitable for verifying the quality properties of the surface.

It follows from the above that the choice of strategy depends mainly on the analysis of the individual extracted parts of the shape surface. The samples must be selected to represent all important and qualitatively complex parts of the future form. Those findings are not applicable in general. Each other shape surface requires analysis of the extracted parts. If uncertainty is already shown during the machining simulation, or during the production of the test specimen, the strategy chosen for the production of the complete product will certainly not be chosen.

\section{Conclusion}

The main goal of the experimental works presented in this article is the importance of verification and subsequent correct choice of strategy in machining shaped surfaces of tools for the manufacturing of components for the automotive industry with high repeatability of production. The presented methodology for verifying the quality of machining of the shaped surface based on the evaluation of roughness allows to choose the most suitable machining strategy. It also points to the possibility of choosing combined strategies. It also examines the time fund for production in a virtual environment and in real production of a sample, which in most cases coincides with reality. The evaluation also includes information on the suitability of the synthetic wood material for verification and evaluation of the resulting surface quality. The experience gained from the experiment demonstrated in this article makes it easier in further work to obtain additional information important for verifying the suitability of the strategy of machining shaped surfaces on parts.

\section{Acknowledgement}

This work has been supported by grant project VEGA 1/0110/18 "Research and development in the area of reverse engineering and rapid prototyping focused on innovations of constructional parts designed for the experimental vehicles and transport equipment".

\section{References}

1. M.P. Groover, Fundamentals of Modern Manufacturing: Materials, Processes and Systems. John Wiley \& Sons, New York, 2010.

2. C.H. Chang, M.A. Melkanoff, NC machine programming and software design. Prentice Hall, New York, 1989.

3. M. Dovica, A. Gmiterko, V. Molnár, Gauge for straightness and perpendicularity measurement, in: MicroCAD '95, Int. Computer Science Conference, Miskolc, 1995, pp. 1-4.

4. J. Fabianová, CAD/CAM systems at shape design and production of plastic products. Transfér inovácií, 9 (2006) 88-90.

5. P. Michalik, J. Zajac, J. Duplák, A. Pivovarník, CAM Software Products for Creation of Program for CNC Machining, Future Communication, Computing, Control and Management, 141 (2012) 421-425.

6. M. Fabian, E. Spišák, J. Šeminský, M. Dovica, P. Ižol, CAM parameters setup and milled concave and convex surface quality, Metalurgija, 49 (2010) 181-185.

7. P. Ižol, J. Beňo, M. Balazs, Precision and Surface Roughness When Free-Form-Surface Milling, Manufacturing Engineering, 10 (2010) 70-73.

8. K. Ahmadi, F. Ismail, Modeling chatter in peripheral milling using the Semi Discretization Method, CIRP Journal of Manufacturing Science and Technology, 5 (2012) 77-86.

9. R.T. Farouki, S. Li, Optimal tool orientation control for 5-axis CNC milling with ball-end cutters, Computer Aided Geometric Design, 30 (2013) 226-239.

10. J. Senatore, S. Segonds, W. Rubio, G. Dessein, Correlation between machining direction, cutter geometry and stepover distance in 3-axis milling: Application to milling by zones, Computer-Aided Design, 44 (2012) 1151-1160.

11. C.K. Toh, A study of the effects of cutter path strategies and orientations in milling, Journal of Materials Processing Technology, 152 (2004) 346-356.

12. P. Ižol, "Porovnanie frézovacích stratégií pre tvarové plochy," Transfer inovácií, no. 20, pp. 18-21, 2011.

13. Ižol, P., Duríček, M., "CAM systémy a hodnocení strategií obrábění," itCAD, vol. 20, no. 6, pp. 32-33, 2010.

14. Madl, J., "Surface Properties in Precise and Hard Machining," 
Manufacturing Technology ${ }_{\text {" }}$ vol. 12, no. 13, pp. 158-166, 2012.

15. S. Kalpakjian, Manufacturing engineering and technology. Wokingham: Addison-Wesley, 1989, p. 1199

16. T. Altan, B. Lilly, and Y. C. Yen, "Manufacturing of Forging dies and Molds," CIRP Annals - Manufacturing Technology, vol. 50, no. 2, pp. 404-422, 2001.

17. Fabianová, J., "CAD/CAM systémy pri návrhu tvaru a výrobe plastových výliskov,"Transfer inovácií, no. 9, pp. 88-90, 2006.

18. K. B. Mawussi and L. Tapie, "A knowledge base model for complex forging forging die machining," Computers \& Industrial Engineering, vol. 61, no. 1, pp. 84-97, Aug. 2011.

19. Yao, Z., Gupta, S. K., "Cutter path generation for 2.5D milling by combining multiple different cutter path patterns," International Journal of Production Research, vol. 42, no. 11, pp. 2141-2161, 2004.

20. J. Tomáš, M., Ižol, P., Draganovská, D., Beňo, "CAD modeling of active surfaces in design of forging dies," Scientific Bulletin of the "Petru Maior" University of Tîrgu Mureş, vol. 9, no. 2, pp. 44-49, 2012.

21. I. Selimovic, "Improved algorithms for the projection of points on NURBS curves and surfaces," Computer Aided Geometric Design, vol. 23, no. 5, pp. 439-445, Jul. 2006

22. M. Fabian, P. Ižol, D. Draganovská, M. Tomáš, "Influence of the CAM Parameters and Selection of End-Mill Cutter when Assessing the Resultant Surface Quality in 3D Milling, Applied Mechanics and Materials, vol. 474 (2014) pp 267272. 